\title{
EFEITO DE BACILLUS THURINGIENSIS (BT) SOBRE LAGARTAS DE SPODOPTERA FRUGIPERDA E ANTICARSIA GEMMATALIS EM LABORATÓRIO
}

\author{
Fabrício Oliveira Fernandes ${ }^{1}$ \\ Liliane Nachtigall Martins ${ }^{2}$ \\ Tiago Scheunemann ${ }^{3}$ \\ Adilson Härter ${ }^{4}$ \\ Ana Paula Stori de Lara ${ }^{5}$ \\ Gustavo Sessa Fialho ${ }^{6}$
}

\begin{abstract}
Resumo: Anticarsia gemmatalis (lagarta-da-soja) e Spodoptera frugiperda (lagarta-do-cartucho) são insetos polífagos e desfolhadores, responsáveis por prejuízos em diversas culturas. O objetivo deste trabalho é avaliar a mortalidade desses insetos através do consumo de dieta artificial com a adição de cepas de Bacillus thuringiensis (Bt). Para a realização dos experimentos foram utilizadas 30 lagartas de A. gemmatalis $\left(3^{\circ}\right.$ instar) e S. frugiperda $\left(1^{\circ}\right.$ instar) para cada tratamento, as quais foram acondicionadas em tubos de vidro esterilizados contendo $1 \mathrm{~cm}^{3}$ de dieta artificial. Posteriormente foram adicionadas alíquotas de 150 $\mu$ l de Bt var israelensis (Bti), Bt var kurstaki (Btk), Bt var oswaldo cruz (Bto) e água destilada para o controle. O tratamento com Btk resultou em maior mortalidade ambas espécies, seguidas por Bto para A. gemmatalis e Bti para S. frugiperda.
\end{abstract}

Palavras-chave: Lagarta-do-cartucho; Lagarta-da-soja; Biotecnologia; Controle biológico.

\footnotetext{
${ }^{1}$ Universidade Federal de Pelotas/Entomologia. E-mail: fabriciof9@gmail.com.

2 Universidade Federal de Pelotas/Entomologia. E-mail: lilinachtigall@hotmail.com.

3 Universidade Federal de Pelotas/Fitossanidade. E-mail: tiago.scheunemann@hotmail.com.

${ }^{4}$ Universidade Federal de Pelotas/Fitotecnia. E-mail: adilsonharter@gmail.com.

5 Universidade Federal de Pelotas/Microbiologia. E-mail: ana.paula.central@hotmail.com.

${ }^{6}$ Universidade Federal de Pelotas/Física e Matemática. E-mail: gsfialho@hotmal.com.
} 